\title{
Phí tổn của chủ nghĩa tư bản thân hữu: Lý thuyết và thực tiễn ở một số quốc gia Châu Á
}

\section{Costs of crony capitalism: Theory and reality in some Asian countries}

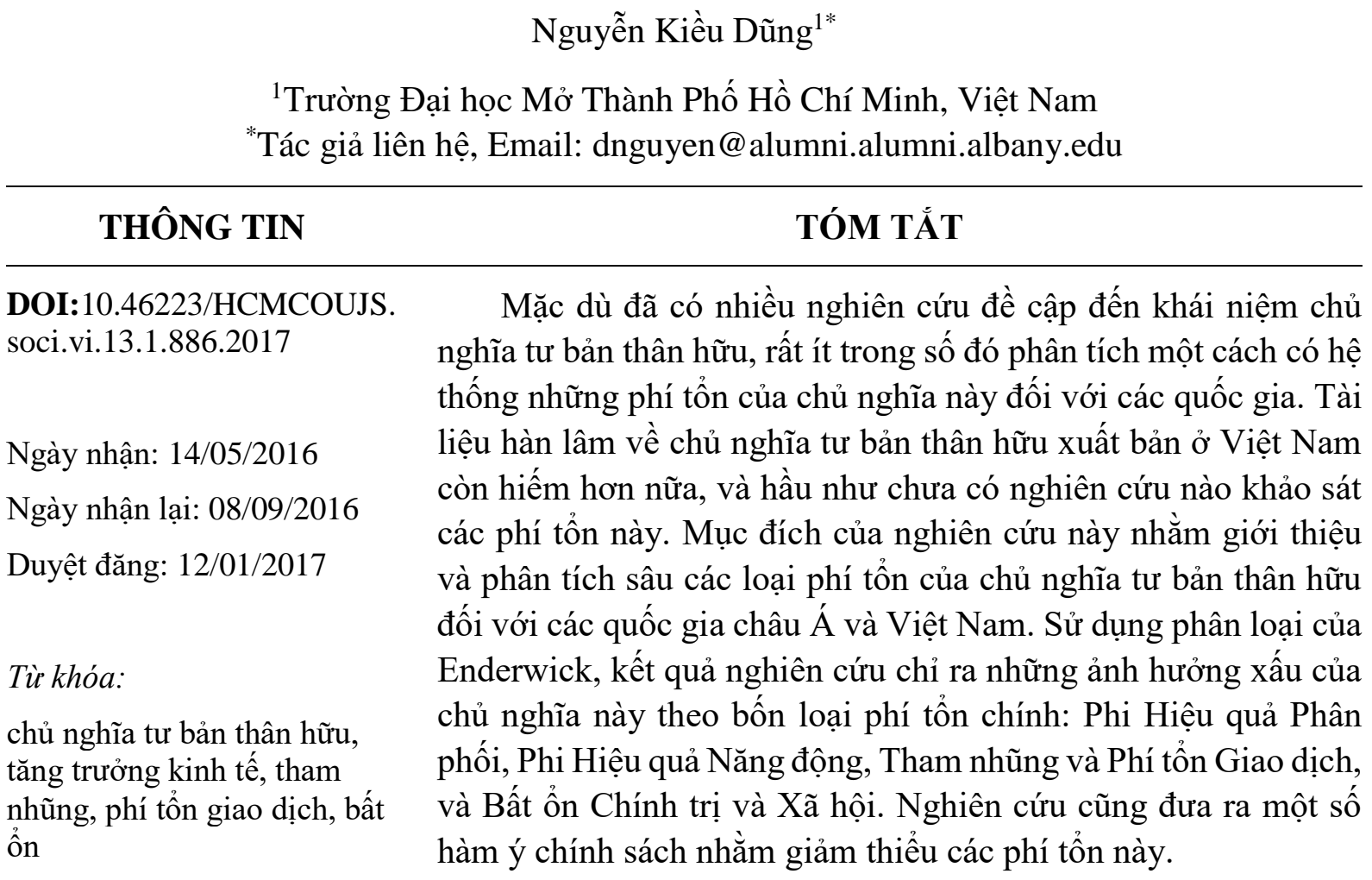

\begin{abstract}
Although there have been many studies on the notion of crony capitalism, very few of them systematically investigated the costs of capitalism for nations. Academic works on crony capitalism published in Vietnam are rarer, and almost none examines these costs. The purpose of the study is to introduce and thoroughly analyze the costs of crony capitalism for Asian countries and Vietnam. Using the classification of Enderwick, the findings of the study point out the adverse effects of capitalism under four main types of costs: Allocative Inefficiency, Dynamic Inefficiency, Corruption and Transaction Costs, and Social and Political Instability. The study also provides some implications in order to minimize these costs.
\end{abstract} Keywords: crony capitalism, economic growth, corruption, transaction costs, instability 


\section{Giới thiệu}

Chủ nghĩa Tư bản Thân hữu (CNTBTH) là khái niệm giao thoa giữa kinh tế học và khoa học chính trị, bao gồm kinh tế chính trị về phát triển, tham nhũng, quản trị doanh nghiệp, và dân chủ hóa. CNTBTH đề cập đến mối quan hệ đặc biệt giữa những người nắm quyền lực với một nhóm doanh nghiệp có tiềm lực tài chính hoặc có quan hệ thân tộc để trao những đặc quyền kinh tế nhằm đổi lấy những lợi ích tài chính. Các doanh nghiệp này tương tự như các công ty độc quyền do vua Anh tạo ra hồi cuối thế kỷ thứ 16 (Calabresi \& Price, 2012; MacIntyre, 2006). Những hình thức ưu đãi dành cho nhóm doanh nghiệp này bao gồm chính sách thuế đặc biệt, những khoản trợ giúp, đầu tư từ ngân sách, hoặc những hình thức trợ giúp khác mà các doanh nghiệp khác không thể tiếp cận được. Sự thành bại của các doanh nghiệp này lệ thuộc phần lớn vào các ưu đãi của quan chức chính phủ. Do vậy, dù một nền kinh tế trên danh nghĩa là kinh tế thị trường, mối quan hệ với giới cầm quyền sẽ là yếu tố quyết định sự phát triển chứ không phải năng lực cạnh tranh của doanh nghiệp. Giới nghiên cứu quốc tế đã đạt được sự nhất trí cao rằng CNTBTH tạo ra đặc lợi dẫn tới phân bổ sai tài nguyên, cản trở việc tạo ra của cải và cải cách cơ chế. Thêm vào đó, tham nhũng đi kèm với CNTBTH cũng là trở lực cho tăng trưởng và phát triển, phá hoại sự cạnh tranh lành mạnh của các nền kinh tế thị trường.

Mặc dù đã có nhiều tài liệu hàn lâm đề quốc gia châu Á và Việt nam làm đối tượng phân tích. Mặc dù trong một số điều kiện nhất định CNTBTH thúc đẩy tăng trưởng kinh tế và làm giảm phí tổn giao dịch, những phí tổn của chủ nghĩa này vẫn vượt xa những lợi ích mà nó đem lại cho xã hội nói chung. Dựa trên sơ đồ phân loại của Enderwick, nghiên cứu này bổ sung những luận cứ nhằm làm sáng tỏ các vấn đề liên quan phí tổn của $\mathrm{CNTBTH}$ ở một số quốc gia châu Á và Việt nam.

\section{Cơ sở lý thuyết}

Theo Enderwick (2005), các phí tổn của CNTBTH có thể được phân chia thành 4 loại: Phi hiệu quả Phân phối (Allocative Inefficiency), Phi hiệu quả Năng động (Dynamic Inefficiency), Tham nhũng và Phí tổn Giao dịch (Corruption and Transaction Costs), và Bất Ổn Chính trị và Xã hội (Social and Political Instability).

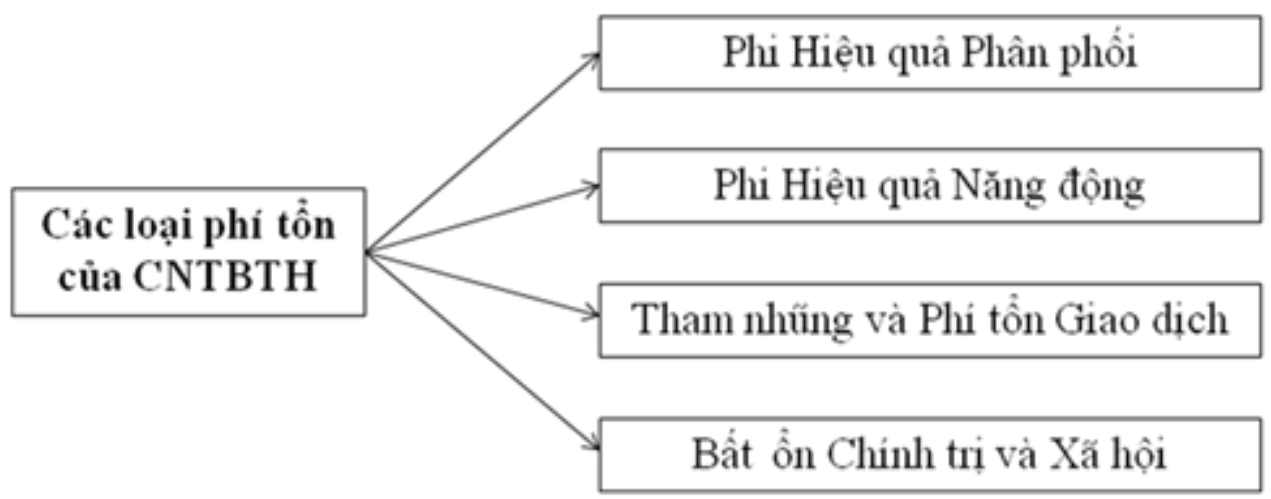

Hình 1.

Phân phối kém hiệu quả xảy ra khi các nguồn tài nguyên được phân bổ cho các đối tượng khác với tỷ lệ và đối tượng trong điều kiện của thị trường cạnh tranh. Đây là phí tổn được quan tâm nhiều nhất, cho dù chỉ là một trong những phí tổn quan trọng của CNTBTH. 
Hiệu quả năng động đề cập đến hiệu quả phân phối được tích tụ theo thời gian thay vì chỉ tính ở một thời điểm. Khi các lực lượng kinh tế trên thế giới trở nên ngày một tự do nhờ các quá trình bãi bỏ luật lệ, tự do hóa và toàn cầu hóa, tính phi hiệu quả năng động cũng tăng theo. Các ngân hàng có xu hướng thích cho các công ty được nhà nước bảo hộ vay trước sức ép cạnh tranh khốc liệt. Hành vi này dẫn đến kém sáng tạo và đổi mới, ít đầu tư nâng cấp công nghệ do các công ty được bảo hộ cảm thấy không cần triển khai các hoạt động mới hoặc theo đuổi việc đa dạng hóa. Với sự có mặt của CNTBTH, hành vi này còn khiến thị trường tài chính kém phát triển cũng như thiếu vắng các công ty nước ngoài. Tất cả những điều này khiến tính năng động trở nên phi hiệu quả.

CNTBTH còn đi kèm với mức độ tham nhũng cao. Trong một số trường hợp, tham nhũng liên quan đến một nhóm nhỏ quan chức và doanh nghiệp, nhưng trong hầu hết các trường hợp khác, tham nhũng là một đại dịch. Tham nhũng kéo theo cả phí tổn giao dịch và sự rủi ro. Phí tổn giao dịch là các chi phí tạo ra, giám sát và thúc đẩy thực thi hợp đồng giữa các bên. Phí tổn này phụ thuộc vào môi trường thể chế. Mối quan hệ giữa chính phủ và giới doanh nhân tinh hoa ở mỗi nước mỗi khác và mỗi quốc gia phải đối mặt với sức ép quốc tế khác nhau, xuất phát điểm khác nhau và điều kiện phát triển khác nhau. Thường thì tham nhũng làm tăng phí tổn giao dịch và do vậy dẫn đến giảm khối lượng đầu tư, cả nguồn đầu tư trong và ngoài nước. Nhìn chung, tham nhũng khuyến khích tìm kiếm đặc lợi, một hoạt động đối lập với việc tạo ra của cải.

Ngoài ra, CNTBTH tạo ra bất bình đẳng kinh tế và bất ổn xã hội bởi đầu tư cho cơ sở hạ tầng thiên về những công trình phục vụ tầng lớp giàu có. Những người thu nhập thấp phải chịu thuế cao hơn và được hưởng ít dịch vụ hơn. Tham nhũng làm tăng bất ổn xã hội bởi ảnh hưởng đến tốc độ tăng trưởng, giảm cơ hội giáo dục của người nghèo và khuyến khích các chính sách ủng hộ bất bình đẳng về sở hữu tài sản, thuế, và chi tiêu xã hội. CNTBTH còn làm ảnh hưởng đến quá trình điều chỉnh cơ cấu chính trị do ngăn cản việc tạo ra cơ chế để điều tiết, giám sát minh bạch và cân bằng giữa tăng trưởng và ổn định (Godement, 1999; Rose-Ackerman, 1997).

\section{Phát triển và ứng dụng lý thuyết}

Bài viết này là một nghiên cứu kết hợp lý luận với thực tiễn, với mục tiêu phát triển và bổ sung những luận cứ vào phân loại của Enderwick để làm sáng tỏ các dạng phí tổn của CNTBTH. Nghiên cứu này giới hạn phạm vi trong các phí tổn của CNTBTH ở các quốc gia châu Á bởi nhóm quốc gia này nằm trong khu vực có ảnh hưởng cao đến Việt Nam.

\subsection{Phi hiệu quả phân phối}

Theo Lý thuyết Kinh tế Tân cổ, các công ty nhà nước không thể đem đến hiệu quả sản xuất cao bởi sự can thiệp chính trị khiến cho các nhà quản lý không được khuyến khích đầy đủ, bị trả lương thấp, dẫn đến điều hành kém. Thêm vào đó, khi các công ty nhà nước chiếm tỷ trọng đáng kể trong GDP, các công đoàn có xu hướng hoạt động mạnh mẽ hơn ở cấp địa phương và quốc gia. Những điều này dẫn tới giảm hiệu quả sản xuất hàng hóa công. Lý thuyết Quyền Tư hữu cho rằng các chủ sở hữu tư nhân quản lý hiệu quả hơn bởi tối ưu hóa lợi nhuận của chính những người này và giá trị của các quyền sở hữu. Ngoài ra, mối quan hệ chủ-thợ ở khu vực tư nhân được cho là đơn giản hơn khu vực công, bởi các cổ đông nắm được thông tin từ 
các báo cáo công khai và dễ dàng giám sát và trừng phạt nhà quản lý khi cần (Uddin, 2015). Tuy nhiên, quá trình tư nhân hóa lại kéo theo việc móc nối giữa các chính trị gia và một số chủ doanh nghiệp tư nhân để bí mật phân phối các đặc lợi, điều mà người ta thường gọi là CNTBTH.

CNTBTH dẫn đến phân bố tài nguyên phi hiệu quả bởi tạo ra một tập hợp các chính sách cung cấp đặc quyền cho một nhóm sở hữu tài sản nào đó với tỷ lệ thu lời cao nhằm khuyến khích họ đầu tư. Có nghĩa là CNTBTH không chỉ cho phép tìm kiếm đặc lợi (rent-seeking) mà còn phân phối đặc lợi. Nhóm nắm giữ tài sản này sẽ phải chia sẻ lợi ích với một số các nhà hoạch định chính sách đã phân bổ đặc lợi cho nhóm để đảm bảo tiếp tục những hợp đồng ngầm giữa nhóm với các chính trị gia này. Chính những điều này thúc đẩy sự hình thành độc quyền và độc quyền nhóm (Haber, 2002). Bai, Chang-Tai, và Song (2014) lập luận rằng điều kiện tiên quyết để có một nhà tư bản thành công ở Trung Quốc là thân thiết với các lãnh đạo chính trị. Trong bối cảnh các thể chế chính thức ở Trung Quốc còn yếu kém, cách duy nhất để doanh nhân thành công là xây dựng mối quan hệ đặc biệt với các chính trị gia để có thể vượt qua rừng luật lệ để được độc quyền truy cập các tài nguyên. Dĩ nhiên, cách làm này khá phổ biến ở các quốc gia có thể thể chính thức yếu chứ không chỉ riêng Trung Quốc. Bangladesh là một ví dụ khác. Theo Uddin (2015), Quỹ Tiền tệ Quốc tế, Ngân hàng Thế giới, và các quốc gia phương tây đã cung cấp các hạ tầng công nghệ và năng lực tổ chức để thúc đẩy quá trình tư nhân hóa nhưng lại không quan tâm lắm đến vấn đề pháp lý và bảo vệ người lao động. Trên thực tế, việc tư nhân hóa ở Bangladesh đã dẫn tới tái phân phối quyền lực và của cải vào một số chủ sở hữu mới và thúc đẩy sở hữu gia đình, tư bản thân hữu, và các thể chế chuyên quyền kiểm soát người lao động.

Một số người nghĩ rằng $\mathrm{CNTBTH}$ đơn thuần là cưỡng ép tái phân phối từ người này sang người khác và do vậy là một trò chơi tổng-bằng-không. Tuy nhiên theo Henderson (2012), điều này sai bởi tư bản thân hữu là trò chơi tổng âm theo nghĩa trong quá trình tái phân phối, CNTBTH phá hủy của cải, thậm chí phá hủy nhiều của cải trong quá trình phân bổ so sánh với số lượng của cải đến tay các đối tác được chọn. Điều này rất khác với các giao dịch trên thị trường tự do, khi cả người mua và người bán đều có lợi hoặc là cả hai bên không liên quan đên giao dịch. CNTBTH còn hủy hoại của cải bởi khuyến khích các công ty sử dụng tài nguyên tác động đến những người nắm quyền hoạch định chính sách. Ví dụ các công ty chi tiền để vận động hành lang một chính sách thuế khóa để được độc quyền sản xuất hoặc bán một số sản phẩm nào đó. Số tiền này là một tổn thất xã hội. Theo quan sát của Anders Aslund, Viện Kinh tế Quốc tế Peterson, việc phân phối đặc quyền khai thác dầu hỏa ở Nga của Putin không tuân theo nguyên tắc đạo đức lẫn giá trị kinh tế. Trong nhiệm kỳ tổng thống thứ hai, Putin đã thường xuyên vi phạm các quyền tư hữu bằng việc sung công và tái quốc hữu hóa các doanh nghiệp lớn của nhà nước đã được tư nhân hóa sau khi Liên xô tan rã (Roberts, 2010). Đương nhiên phân phối phi hiệu quả không nhất thiết làm giảm tăng trưởng kinh tế, nhưng có thể đưa đến những hệ lụy khác, chẳng hạn như bất bình đẳng kinh tế. Theo You (2005), chính sách kinh tế đặc thù của Park Chung Hee những năm 1960s, quản lý nhà nước đồng thời khuyến khích các tập đoàn công nghiệp khổng lồ (chaebol), là minh chứng cho điều này. Park đã hỗ trợ các chaebol các khoản vay lãi xuất thấp thông qua ngân hàng nhà nước, và đây cũng là cách cho phép ông ta kiểm soát các tập đoàn này. Chính sách kinh tế lấy chaebol làm trọng tâm đã hình thành nên liên minh giữa chính phủ, chaebol, và các ngân hàng làm tăng bất bình đẳng về thu 
nhập và của cải. Các quan chức chính phủ và các chaebol trao đổi đặc lợi và các nguồn tiền cho mục đích chính trị. Mặc dù chính phủ có vị thế nổi trội ở đầu thời kỳ, khả năng mua quyền ảnh hưởng chính trị của các chaebol tăng lên và nhà nước dần dần bị các tập đoàn này thao túng bởi tham nhũng và bởi nguyên tắc "quá lớn để thất bại".

Không thể kỳ vọng chính phủ luôn là một nhà lập kế hoạch nhân từ theo nghĩa tối ưu lợi ích của toàn xã hội. Các nhà hoạch định chính sách thường quan tâm đến lợi ích của họ khi soạn thảo chính sách mới. Do không được hưởng lợi từ việc ra những quyết định đúng đắn nhưng lại bị trừng phạt bởi các chính sách sai, họ ít có tinh thần doanh nghiệp theo nghĩa dám làm, dám chịu. Theo một nghiên cứu của Niskanen, các quan chức chính phủ thường cố gắng tối ưu lợi nhuận bản thân khiến cho một lượng tài nguyên lớn được họ phân bổ một cách phi hiệu quả. Những người được bầu cử thường đưa ra những chính sách để được tái bầu thay vì để phục vụ lợi ích công cộng (Holcombe, 2012; Niskanen, 1971).

\subsection{Phi hiệu quả năng động}

Olson (1982) lập luận rằng các quốc gia sẽ suy thoái khi các nhóm lợi ích tham gia vào quá trình chính trị khiến cho các công ty giành được nhiều lợi nhuận do quan hệ chính trị hơn là do năng suất kinh tế của chính họ. Một hệ thống chính trị non trẻ thường có các nhóm lợi ích yếu bởi các liên kết chính trị cần thời gian để phát triển và chưa đủ thời gian để đạt tới điểm mà các doanh nghiệp có thể tính đến những ưu đãi từ phía chính phủ. Khi các lợi ích từ chính trị còn yếu doanh nhân sẽ có động lực để chú trọng hơn vào quá trình sản xuất, làm thúc đẩy tăng trưởng. Tuy nhiên theo thời gian, các nhóm lợi ích phát triển đủ lông đủ cánh và tạo lập được mối quan hệ với các quan chức chính phủ. Khi ấy lợi ích từ liên kết chính trị sẽ áp đảo lợi ích từ hoạt động kinh tế, khiến quốc gia đi xuống. Sự thay thế của liên kết chính trị đối với hoạt động kinh tế là một dạng CNTBTH (Holcombe, 2012).

Hiệu quả năng động cũng bị ảnh hưởng bởi các hành vi tham nhũng dẫn đến nhiễu loạn tăng trưởng và rủi ro. Enderwick (2005) đưa ra một lý giải là mọi khoản tiền trả liên quan đến tham nhũng để đạt được một giấy phép đầu tư sẽ làm tăng chi phí của việc đầu tư đó và làm giảm động lực của doanh nhân. Tỷ lệ đầu tư tư nhân thấp kết hợp với sự thất thoát đầu tư công vào tiêu thụ ảnh hưởng xấu đến tốc độ tăng trưởng. Nhưng lời giải thích này không đúng cho mọi trường hợp. Các nghiên cứu trước đây thường cho rằng tham nhũng và tăng trưởng không thể song hành. Điều này có nghĩa là chính phủ không có tham nhũng thúc đẩy tăng trưởng tốt hơn là các chính phủ bị chi phối bởi tham nhũng và CNTBTH. Các nhà kinh tế thường cố lý giải tại sao "bốn con rồng châu Á" không tham nhũng hoặc tại sao tăng trưởng ở một số quốc gia không ngoạn mục như dự kiến. Tuy nhiên, làn sóng tham nhũng những năm 1990 ở Hàn Quốc và Đài Loan cho thấy CNTBTH đôi khi không nghiêm trọng đến thế. Richard Doner và Ansil Ramsey từng lập luận: "Nếu tham nhũng và tìm kiếm đặc lợi có thể hủy hoại tăng trưởng ở một số quốc gia, nhưng không ở một số quốc gia khác, thì chúng ta cần hiểu biết rõ ràng hơn loại tham nhũng và tìm kiếm đặc lợi nào ảnh hưởng đến hoạt động kinh tế trong những hoàn cảnh nào". 


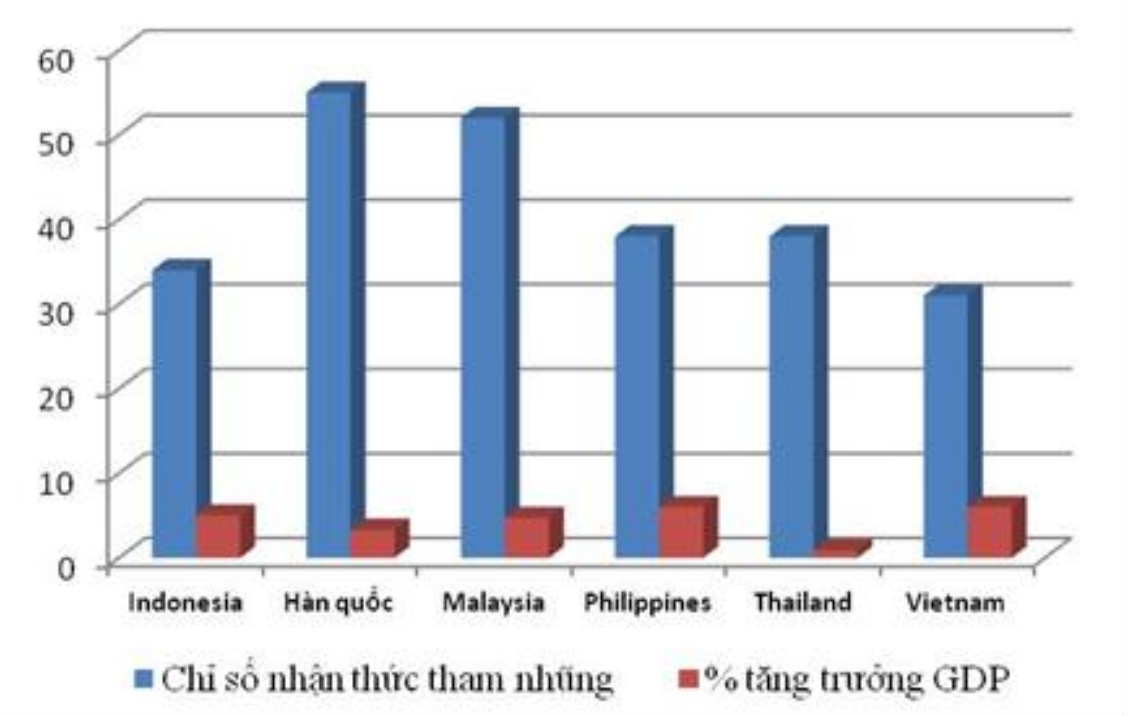

Hình 2. Biểu đồ Chỉ số Nhận thức Tham nhũng và Tốc độ Tăng trưởng Trung bình giai đoạn 2001-2005

Nguồn: Tác giả tổng hợp từ số liệu của Worldbank và Transparency.org

Trước cuộc khủng khoảng tài chính châu Á 1997, Hàn quốc đã chứng kiến sự tăng trưởng đặc sắc trên 30 năm trong khi Philippines thì không. Nhìn vào các kết quả đó người ta tưởng rằng Hàn Quốc ít tham nhũng hơn Philippines. Trên thực tế, cuộc khủng khoảng không diễn ra chỉ trong một đêm và cấu trúc lịch sử dẫn tới khủng khoảng 1997 còn kéo dài sau sự kiện này. Ở cả hai quốc gia này, tham nhũng và tăng trưởng đồng hành với nhau suốt một thời gian dài. Thậm chí trong thời kỳ tăng trưởng nhanh ở Hàn Quốc, toan tính chính trị chứ không phải là hiệu quả kinh tế là yếu tố quyết định cho các chính sách kinh tế. Tuy nhiên các yếu tố đóng góp vào sự tăng trưởng ở Hàn Quốc bị lu mờ trong cuộc khủng khoảng châu Á 1997. Ở Philippines, một tập hợp các yếu tố khác đã góp phần kìm hãm sự phát triển (Kang, 2002, 2003).

\subsection{Tham nhũng và phí tổn giao dịch}

Mức độ tham nhũng cao thường đi kèm với CNTBTH. Bhagwati (2000) phân biệt hai loại tham nhũng: tham nhũng đặc lợi và tham nhũng chia sẻ lợi nhuận. Tổng thống Suharto của Indonesia trước đây thường cấp giấy phép độc quyền sản xuất hoặc phân phối một số sản phẩm cho các thân hữu là tham nhũng đặc lợi, dẫn đến tổn thất xã hội. Tuy nhiên còn có dạng tham nhũng chia sẻ lợi nhuận. Chẳng hạn các thân hữu được chia sẻ cổ phần công ty là một biện pháp khuyến khích hiệu quả kinh tế. Loại tham nhũng thứ hai này có thể lý giải sự tăng trưởng nhanh chóng ở Trung Quốc. Ở mọi nền dân chủ, các chính trị gia thường phải chật vật đấu tranh với ham muốn tham nhũng để có được quyền lực. Khi có sự hiện diện của CNTBTH, không gian kinh tế và chính trị ràng buộc chặt chẽ đến nhau khiến cho chạm tay vào quyền lực có nghĩa là chạm tay vào tài sản và ngược lại. Các doanh nhân giàu có buộc phải duy trì quan hệ với quan chức nhà nước để duy trì đặc quyền, trong khi các chính khách thì ngược lại, đoạt được chiếc ghế quyền lực có nghĩa là có quyền ra quyết định và phân phối lại tài sản (Sharafutdinova, 2011). 
Theo Gray và Kaufmann (1998), tham nhũng làm tăng phí tổn giao dịch, sự bất ổn và làm nhiễu loạn việc phân bổ tài nguyên. Bằng việc tăng phí tổn giao dịch, tham nhũng làm giảm đầu tư trong và ngoài nước, ưu ái các dự án lớn do tiềm năng hối lộ lớn hơn, và khuyến khích mật độ công nghệ lớn hơn mức cần thiết, nghĩa là khuyến khích các hoạt động tìm kiếm đặc lợi thay vì các hoạt động tạo ra của cải. Như đã nêu, mặc dù tham nhũng và CNTBTH thường được coi là cản trở phát triển, trong một số điều kiện nhất định, chúng có thể có lợi cho tăng trưởng. Các lý thuyết về Phí tổn Giao dịch, và Kinh tế Thể chế Mới có thể hỗ trợ giải thích khi nào CNTBTH có tính hủy hoại, khi nào không.

Theo Lý thuyết Kinh tế học Tân cổ, các hợp đồng không mất phí giao dịch và được thực hiện ngay lập tức. Quyền tư hữu được đảm bảo và mọi phân phối tài nguyên ban đầu có thể được đàm phán một cách tự nguyện và trao đổi để tối ưu hiệu quả. Lý thuyết này chống lại mọi sự can thiệp của chính phủ bởi điều này phản lại nguyên tắc của thị trường hoàn hảo. Lý thuyết Kinh tế về Phí tổn Giao dịch cho rằng khi một mối quan hệ với một số lượng vừa đủ quan chức chính phủ và doanh nhân tham gia, phí tổn giao dịch và tổn thất vô ích (deadweight loss) sẽ giảm, trong khi quá nhiều hoặc quá ít số lượng đối tác tham gia sẽ làm tăng tổn thất vô ích do tham nhũng. Phí tổn giao dịch thấp được cho là có lợi cho kinh tế và chính trị nói chung. Điều này giải thích sự khác biệt giữa Hàn Quốc so với Phillippines và Indonesia trước những năm 1990s. Ở Hàn quốc, một số lượng vừa đủ các doanh nhân và chính khách trong mối quan hệ CNTBTH đã dẫn đến giảm phí tổn giao dịch và do vậy, thúc đẩy tăng trưởng. Trong khi đó, Philippines là trường hợp điển hình của quá nhiều thân hữu tham gia vào các mối quan hệ chính phủ-doanh nhân dẫn đến lạm phát cung quyền lực. Các tập đoàn đầu sỏ (oligarchies) can thiệp vào nhà nước thông qua cạnh tranh bầu cử, sau đó chia sẻ lợi ích với các chính trị gia. Những điều này khiến phí tổn giao dịch cao và hiệu quả kinh tế thấp. Indonesia thì ngược lại. Trong thời kỳ ổn định của Suharto, Inonesia đạt được tăng trưởng ấn tượng và nhiều đối tác coi tham nhũng như chi phí ngoại giao với ông ta. Khi quyền lực tập trung vào tay Suharto, nền kinh tế bị bao phủ bởi bảo trợ và tham nhũng, nhưng các quyết định cũng dễ được thông qua. Khi quyền lực của Suharto suy yếu, gia quyến và thân hữu của Suharto lại nắm vai trò ban hành các chính sách. Tuy nhiên, số lượng vừa đủ các đối tác tham gia mối quan hệ thân hữu thường khó xảy ra hơn cho nên CNTBTH nói chung có tính hủy hoại. Lý thuyết Phí tổn Giao dịch nhấn mạnh rằng việc tạo ra, giám sát và thúc đẩy thực hiện hợp đồng dài hạn là bất khả và do vậy việc trao đổi dài hạn và lặp lại các trao đổi tiềm ẩn nhiều nguy cơ. Theo lý thuyết này, một nền kinh tế được coi là năng động khi mà các thể chế giảm thiểu phí tổn giao dịch, quyền tư hữu được đảm bảo, thông tin được minh bạch và các quyền pháp lý và chính trị không bị bẻ cong. Những điều này không thể có ở các quốc gia đang phát triển (Kang, 2003).

Việc tìm kiếm thể chế và phương pháp mà các bên có thể tham gia một cách đáng tin cậy là mục tiêu của Lý thuyết Kinh tế Thể chế Mới. Lý thuyết này đặc biệt hữu ích khi lý giải về $\mathrm{CNTBTH}$. CNTBTH thường bị coi là phá hủy tăng trưởng kinh tế bởi nó đưa đến các quyết định không dựa trên các nguyên tắc của thị trường, tăng phí tổn giao dịch, ngăn cản hiệu quả kinh tế và khuyến khích tìm kiếm đặc lợi. Tuy nhiên đôi khi quan hệ cá nhân làm tăng hiệu quả kinh tế khi các thể chế pháp lý, chính trị, kinh tế đều yếu kém, như thường thấy ở các nước đang phát triển. Thông tin về thị trường vừa hiếm vừa khó đạt tới đồng thời đầu tư và quyền tư hữu không được đảm bảo. Các cam kết dài hạn trở nên khó thực hiện bởi điều kiện kinh tế chính 
trị dễ dàng thay đổi khiến cho phí tổn giao dịch để tạo ra và duy trì các cam kết trở nên rất cao. Các bên cũng ngần ngại ký những cam kết dài hạn do thiếu cơ chế đảm bảo thực hiện cam kết. Trong bối cảnh ấy, CNTBTH có thể giảm phí tổn giao dịch bởi các bên có mối quan hệ sâu sắc và hiểu biết lẫn nhau. Việc giám sát trở nên dễ dàng hơn bởi các bên quá hiểu nhau và dễ dàng trừng phạt bên kia và phát tán thông tin về đối tác. Mặc dù lợi ích dài hạn không được đảm bảo, các bên vẫn có thể dự đoán và đạt được sự ổn định dựa trên quan hệ cá nhân (Kang, 2003). Một ví dụ cho điều này là Hàn quốc. Dưới thời Park Chung Hee, việc nhà nước quản lý vốn khiến cho khả năng cắt giảm tín dụng cho các chaebol bị loại trừ bởi các bên đều hiểu rõ tầm quan trọng của các tập đoàn này đối với quốc gia. Số thân hữu nhỏ và ít khả năng thay đổi dẫn đến chi phí cạnh tranh thấp. Ban đầu các hoạt động kinh doanh bị nhà nước kiểm soát. Tuy nhiên sau đó chính quyền ít quan tâm bởi ngày càng phụ thuộc vào các doanh nhân vì cả mục đích chính trị lẫn phát triển kinh tế. Các hiệp hội doanh nhân do vậy giữ vai trò quan trọng trong việc xây dựng và thúc đẩy thực thi các chính sách. Kang (2002) cho rằng khi quyền lực của nhóm doanh nhân tinh hoa phát triển đến mức áp đảo nhà nước, nhóm này sẽ buộc nhà nước phải nhượng bộ, dẫn đến thúc đẩy tìm kiếm đặc lợi. Khi nhu cầu tìm kiếm đặc lợi trở nên quá lớn, nhà nước không có khả năng thực thi các quyết định và tăng trưởng sẽ bị kìm hãm.

Tuy nhiên Kang (2002) cũng cần nhấn mạnh rằng, tham nhũng chỉ là một biến số ảnh hưởng đến phát triển. Còn nhiều biến số khác chẳng hạn như đe dọa từ bên ngoài, cải cách đất đai, và sự giúp đỡ của các cường quốc. Chính phủ càng lớn, càng cần nhiều quyền lực điều tiết, càng có nhiều tác nhân kinh tế bị áp lực của hệ thống chính trị phải liên quan đến các nhóm thân hữu. Và như vậy người nắm quyền lực chính trị có thể trả giá theo yêu cầu của hệ thống trở thành thân hữu với người được hưởng những ưu đãi chính trị. Áp dụng định lý Coase cho chính trị, Wittman cho rằng $\mathrm{CNTBTH}$ khiến phí tổn giao dịch chính trị đủ thấp, dẫn đến chính phủ phân bổ tài nguyên hiệu quả. Tuy nhiên động cơ của thị trường và chính phủ khác nhau bởi chính phủ có thể cưỡng bức chuyển giao tài nguyên từ người này sang người khác mà không cần đến sự đồng ý của chủ tài nguyên. Trong khi trao đổi trên thị trường đòi hỏi sự đồng ý của tất cả các bên (Kang, 2002, 2003).

\subsection{Bất ổn chính trị và xã hội}

Tính minh bạch thấp là đặc điểm của các xã hội với các thể chế dân sự yếu, truyền thông bị hạn chế, những đặc điểm ngăn cản điều chỉnh và tái cấu trúc kinh tế. CNTBTH còn được cho là nguyên nhân chủ yếu dẫn đến khủng khoảng tài chính châu Á năm 1997. Cuộc khủng khoảng này đã làm thay đổi chóng mặt cách đánh giá nhiều quốc gia châu Á. Chẳng hạn Hàn quốc đang được coi là một hình mẫu phát triển chỉ sau một đêm trở thành một quốc gia nơi mà CNTBTH và tham nhũng hoành hành bạo lực. Sự can thiệp sâu sắc của chính phủ vào hoạt động kinh doanh có thể bao gồm cả hai mặt: tích cực và tiêu cực. Tích cực là ở chỗ điều tiết các hành vi sai của thị trường. Tuy nhiên những người chống lại $\mathrm{CNTBTH}$ cho rằng ủng hộ sự can thiệp của chính phủ chỉ làm tăng sự thông đồng giữa chính khách và doanh nhân và dẫn tới tham nhũng (Enderwick, 2005; You, 2005).

Theo Enderwick (2005), việc chống lại cải cách có thể tiến hành theo một trong ba cách. Cách thứ nhất là 'bắt làm tin', có nghĩa là khi chính quyền và doanh nhân phụ thuộc vào nhau. Sự thay đổi của một bên sẽ đe dọa lợi ích của bên kia khiến cho không bên nào có thể đi trệch 
khỏi quỹ đạo. Điều này đã xảy ra ở Hàn quốc. Mặc dù tái cấu trúc được ghi nhận là quá trình cần phải thực hiện từ lâu, nhiều thế hệ chính phủ kế tiếp nhau đã không có hành động gì đáng kể để thực hiện bởi các chaebol tìm mọi cách ngăn cản quá trình này. Cách thứ hai là khi tham nhũng đã trở thành đại dịch khiến cho những thay đổi chính trị lớn cũng không loại bỏ được CNTBTH. Điều này đã xảy ra ở Indonesia, khi mà chính quyền mới sau Suharto đơn giản là thay gia đình trị bởi nhiều tập đoàn đầu sỏ có quan hệ mật thiết với các quan chức chính quyền, (Wee, 2002). Cách thứ ba là 'thao túng chính phủ', thường xảy ra ở các quốc gia chuyển đổi, khi một nhóm các doanh nghiệp lấn át và buộc chính phủ phải đề ra những điều luật có lợi cho họ. Mặt tối của quá trình này là một nhóm nhỏ doanh nghiệp đạt được những hàng hóa công khan hiếm, làm hỏng quá trình tạo ra của cải và khuyến khích tìm kiếm đặc lợi, dẫn đến phi hiệu quả kinh tế. Thêm vào đó, cộng đồng doanh nghiệp nói chung phải trả giá cho lợi ích của một nhóm nhỏ các doanh nghiệp (Hellman \& Kaufmann, 2001).

Stiglitz (2000) từng nhấn mạnh rằng ổn định chính trị và xã hội rất quan trọng bởi bất ổn để lại hậu quả lâu dài lên tăng trưởng, chẳng hạn tăng trưởng chậm lại sau khủng khoảng vài năm. Trên thực tế một nền kinh tế đã suy sụp mạnh không bao giờ hoàn toàn phục hồi theo nghĩa sản lượng không thể trở lại mức đã từng đạt được. Ngoài ra, bất ổn gây hậu quả lên phân phối, đặc biệt ở các quốc gia đang phát triển. Cuộc khủng hoảng châu Á năm 1997 đã tăng tỷ lệ thất nghiệp lên cao ở Hàn Quốc, Thái Lan, Indonesia trong khi mức lương thực tế giảm 10\% ở Hàn quốc và $25 \%$ ở hai quốc gia còn lại. Nhiều người cho rằng cuộc khủng hoảng này đã khiến "con hổ tương lai" Thái lan không thể xuất hiện. Tuy nhiên một số ý kiến khác lại cho rằng bất ổn chính trị ở Thái lan mới là nguyên nhân chính khiến năm 2013, Quỹ vì Hòa bình, tổ chức nghiên cứu Chỉ số Thành bại Quốc gia, xếp Thái lan vào nhóm cần phải cảnh giác (Ho, 2014).

\section{Thảo luận về trường hợp Việt Nam}

Ở Việt Nam, tài liệu nghiên cứu về CNTBTH vẫn còn rất hiếm mặc dù thuật ngữ này không mới. Tuy nhiên, có thể tính đến những nghiên cứu về các chủ đề liên quan chẳng hạn như tham nhũng, hối lộ, và lợi ích nhóm. Các điều kiện cần thiết để hình thành CNTBTH như hệ thống luật pháp và các thể hoạch định chính sách thị trường yếu, sự phụ thuộc của các ngân hàng, các cổ đông kém tích cực, và áp lực độc lập tài chính không mạnh thì Việt Nam đã hội tụ dầy đủ.

Như trên đã nêu, phi hiệu quả phân phối là hậu quả tất yếu của CNTBTH. Dấu hiệu của CNTBTH ở Việt nam được ghi nhận một cách rõ nét trong giới doanh nhân, quan chức chính phủ, và cả trong các tài liệu chính thức. Vo (2015) cho biết, theo một điều tra năm 2012 của Thanh tra Chính phủ với sự hỗ trợ của Ngân hàng Thế giới, 50\% doanh nghiệp được hỏi cho biết nhóm doanh nghiệp có quan hệ với quan chức chính phủ ngày càng tác động mạnh mẽ hơn đến quá trình hoạch định chính sách, trong khi chỉ 10\% phản đối điều này. Cuối tháng 5/2015, trong một cuộc họp về đấu tranh chống buôn lậu thuốc lá, Thủ tướng Nguyễn Tấn Dũng đã nêu rõ: "Cán bộ bao che, tiếp tay, bảo kê cho buôn lậu chứ các đối tượng cầm đầu không tài giỏi đến mức các cơ quan chức năng không biết và không xử lý được". Đương nhiên sự bao che, tiếp tay, bảo kê cho buôn lậu được đổi lại bằng tiền, hoặc các lợi ích vật chất và dịch vụ khác. Giáo sư Lê Quốc Lý cho biết tuy chưa có thống kê chính thức, dư luận về hiện tượng các doanh 
nghiệp trả tiền cho một số quan chức dưới hình thức cung cấp dịch vụ VIP miễn phí như chơi golf, du lịch, chi phí du học cho con cái, etc...đã khá phổ biến. Một nguy cơ được các tác giả cảnh báo là tuy các nhóm lợi ích đều muốn tác động lên quá trình hoạch định chính sách, các nhóm thân hữu do có tiềm lực kinh tế mạnh hơn sẽ chiến thắng. Đặc biệt, khi những luật về vận động hành lang chưa đầy đủ và chặt chẽ thì các tác động này càng trở nên mạnh mẽ (Le, 2014; D. H. Nguyen, 2014).

Tính phi hiệu quả năng động ở Việt nam thể hiện ở tốc độ tăng trưởng khá nhưng mức độ rủi ro do tham nhũng lớn cũng cao. Theo Brady (2013), nếu chỉ tính riêng tiêu chí tăng trưởng GDP, Viet Nam là một quốc gia hiệu quả. Tuy nhiên bất bình đẳng thu nhập đang tăng mạnh và tham nhũng luôn ở mức cao, theo đánh giá của của tổ chức Minh bạch Quốc tế. Tốc độ tăng trưởng trung bình của Việt Nam giai đoạn 2010-2014 ở mức khá, 5-6\%/năm, nhưng vẫn còn thấp hơn hầu hết các nước trong khu vực như Lào, Campuchia, Miến điện. Để đuổi kịp Trung Quốc và Thái Lan, Việt Nam phải duy trì tốc độ tăng trưởng $7 \%$ mỗi năm trong vòng 20 năm liên tục, điều được cho là bất khả nếu tính tới khoản nợ công 110 tỷ USD, (Huyen, 2015). Truong (2015) cho rằng nhóm lợi ích xuất hiện ở mọi lĩnh vực ở Việt Nam, đặc biệt là ở các khu vực quản lý doanh nghiệp nhà nước, các dự án đầu tư, nhất là đầu tư công, ngân sách quốc gia, thuế, ngân hàng và các thể chế tài chính, nguồn vốn và các dự án đầu tư xã hội, tài sản, đất đai, bất động sản, nguồn khoáng sản, xuất/nhập khẩu, quản lý cán bộ và công chức nhà nước, và quản lý giấy phép. Mạng lưới quan hệ tiền-quyền đã phát triển mạnh cả ở phạm vi lẫn cấp độ, phá hủy nghiêm trọng tài nguyên quốc gia, làm giảm hiệu quả đầu tư. Nhà nước cần một sự đột phá mạnh mẽ trong cải cách cơ chế thì mới hi vọng thay đổi được tình thế.

Về tham nhũng và chi phí giao dịch, lý thuyết Kinh tế Thể chế Mới cũng có thể được áp dụng để giải thích trường hợp Việt Nam. McMillan và Woodruff (1998) đã tiến hành điều tra các doanh nghiệp tư nhân ở Việt Nam và nhận thấy mạng lưới quan hệ đã khuyến khích các hoạt động đầu tư và hối thúc thực thi hợp đồng, khi mà các thể chế chính thức còn thiếu vắng và cơ chế thúc đẩy thi hành luật còn yếu. Các cá nhân và doanh nghiệp dựa vào uy tín của nhau trong mạng lưới quan hệ để tiến hành các giao dịch thương mại. Như vậy mối quan hệ thân hữu đã giúp đỡ giảm chi phí và tăng chất lượng thông tin. Cũng cần phải nói thêm rằng Việt Nam có truyền thống ưu ái các doanh nghiệp nhà nước, bởi chính phủ coi các công ty này là "quả đấm thép" thúc đẩy nền kinh tế. Do mối quan hệ tín hữu khắng khít giữa các công ty nhà nước và các chính trị gia, tham nhũng ít gây ra tác động xấu lên khối doanh nghiệp này hơn khu vực tư nhân. T. Nguyen và Dijk (2012) cũng đưa ra một kết luận tương tự rằng tham nhũng có ảnh hưởng tiêu cực lên sự tăng trưởng của khối doanh nghiệp tư nhân nhưng không ảnh hưởng đến khối doanh nghiệp nhà nước. Nhưng tựu trung, sự ưu ái đối với khu vực nhà nước đã làm biến dạng cơ chế của kinh tế thị trường và có thể gây hại đến tăng trưởng kinh tế bởi sự ưu ái này gây tổn hại cho khu vực tư nhân.

Cuối cùng là mối quan hệ giữa CNTBTH và sự ổn định chính trị xã hội. Nhiều chuyên gia đã cảnh báo các nhóm thân hữu, nhất là các nhóm tư bản tài chính, dễ phát triển thành độc quyền, gây hại lợi ích công và sự ổn định và phát triển lành mạnh của xã hội ở Việt Nam. Trong một nền kinh tế thị trường, mặc dù có sự cạnh tranh giữa các nhóm lợi ích, các nhóm tư bản thân hữu là những nhóm có tiềm năng kinh tế mạnh và quan hệ thân hữu lâu bền với các chính khách hơn cả, cho nên có nhiều khả năng thắng thế trong việc tác động lên quá trình hoạch định 
chính sách. Đặc biệt trong bối cảnh Việt Nam, khi mà những luật về vận động hành lang chưa đầy đủ và chặt chẽ, sự chi phối của các nhóm TBTH sẽ xâm hại nghiêm trọng đến lợi ích của các nhóm khác trong xã hội. Tuy nhiên, những ảnh hưởng ghê gớm nhất của các nhóm tư bản thân hữu là gây thiệt hại lớn về tài sản, từ đó hủy hoại niềm tin của công dân và các giá trị đạo đức xã hội, ảnh hưởng lâu dài đến sự tồn vong của quốc gia, D. H. Nguyen (2014).

\section{Kết luận và hàm ý chính sách}

Hoạt động của các nhóm tư bản thân hữu đôi khi có ý nghĩa tích cực như một hình thức dân chủ đại diện, làm tăng cường hiệu quả của quá trình hoạch định chính sách ở các quốc gia châu Á và Việt Nam. Tuy nhiên các nhóm này thường phát huy những hệ lụy xấu đến nền kinh tế nhiều hơn là điều tốt. Dưới đây là một số gợi ý chính sách nhằm giảm phí tổn của CNTBTH.

Biện pháp quan trọng trước tiên là giảm quyền lực chính phủ ở Việt Nam bằng cách giảm bớt các điều luật và các trợ cấp đặc biệt từ chính phủ đối với các nhóm doanh nghiệp, bởi khi quyền lực chính phủ càng lớn, càng có nhiều sự phân bổ tài nguyên dựa trên quan hệ chính trị. Ngay cả các công ty không muốn dính vào các mối quan hệ thân hữu cũng buộc phải tham gia các mối quan hệ này để duy trì lợi nhuận. Việc giảm can thiệp của chính phủ vào thị trường cũng sẽ làm giảm chi phí ban hành chính sách đồng thời khuyến khích các doanh nghiệp tham gia các hoạt động kinh tế, dẫn đến tăng ổn định chính trị xã hội và thúc đẩy tăng trưởng.

Biện pháp thứ hai là phải xây dựng cấu trúc thuế và chi tiêu chính phủ phải bền vững để chống lại những nỗ lực bẻ cong của các nhóm thân hữu. Cần học tập các quốc gia đã có kinh nghiệm giải quyết CNTBTH để xây dựng cấu trúc thuế và chi tiêu này.

Biện pháp thứ ba là thường xuyên luân chuyển những lãnh đạo quản lý khối doanh nghiệp. CNTBTH tồn tại dựa trên mối quan hệ giữa một nhóm doanh nhân giàu có với một nhóm chính trị gia. Khi các chính trị gia mất ghế thì mối quan hệ thân hữu cũng mất hiệu lực. Chính vì vậy, thường xuyên thay đổi những người phụ trách khối này là điều cần thiết. Cơ chế Kiểm tra-và-Cân bằng (check-and-balance) cũng rất hữu ích để các nhóm lợi ích trong xã hội dân sự tham gia nhiều hơn vào quá trình giám sát, nhằm chống lại lạm dụng quyền lực. Cần tạo ra các chương trình cho phép mọi thành phần kinh tế có thể truy cập để giảm thiểu các cơ hội tìm kiếm đặc lợi đồng thời gia tăng ổn định chính trị. Một điều quan trọng nữa cần phải tính đến là quản trị xung đột lợi ích giữa nhóm thân hữu với các nhóm khác trong xã hội.

Ngoài ra, các biện pháp khác có thể thực hiện là hợp pháp hóa quy trình vận động hành lang (lobby) và cải tổ quá trình hoạch định chính sách. Cần tăng cường tự do hóa thương mại thay vì các loại thuế khóa, hạn ngạch và các hạn chế nhập nhẩu. Đơn giản hóa quy trình hoạch định chính sách, đồng thời đảm bảo các chính sách được minh bạch và có trách nhiệm giải trình. Nhiều mối quan hệ thân hữu độc quyền được tạo ra chính từ luật pháp. Chính vì vậy cần phải cải tiến quy trình pháp luật để giảm thiểu việc tạo ra những mối quan hệ này. 


\section{Tài liệu tham khảo}

Bai, C. -E., Chang-Tai, H., \& Song, Z. (2014). Crony capitalism with Chinese characteristics. Retrieved February 15, 2015, from https://cowles.yale.edu/sites/default/files/files/conf/2014/ma_song.pdf

Begley, T., Naresh, K., \& Eric, T. (2010). Networks and cronyism: A social exchange analysis. Asia Pacific Journal of Management, 27, 281-297.

Bhagwati, J. (2000). Crony capitalism: Rent-creating versus profit-sharing corruption. In The wind of the hundred days: How Washington mismanaged globalization. Cambridge, MA: MIT Press.

Brady, B. (2013). The relationship between economic growth and corruption: The case of Vietnam. $\quad$ Retrieved 16, February 2015, from https://journalistsresource.org/studies/international/development/relationship-economicgrowth-corruption-case-vietnam/

Calabresi, S., \& Price, L. (2012). Monopolies and the constitution: A history of crony capitalism (Working Paper No. 214). Chicago, IL: Northwestern University School of Law.

Enderwick, P. (2005). What's bad about crony capitalism? Asian Business \& Management, 4, 117-132.

Godement, F. (1999). The downsizing of Asia. London, UK: Routledge.

Gray, C., \& Kaufmann, D. (1998). Corruption and development. Finance and Development, 3, $7-10$.

Haber, S. (2002). Introduction: The political economy of crony capitalism. In Crony capitalism and economic growth in Latin America: Theory and evidence. Washington, DC: Hoover Press.

Hellman, J., \& Kaufmann, D. (2001). Confronting the challenge of state capture in transition economies. Finance and Development, 38, 31-35.

Henderson, D. R. (2012). The economics and history of cronyism. Retrieved February 20, 2015, from https://www.mercatus.org/publications/government-spending/economics-andhistory-cronyism

Ho, Q. S. (2014). Khoa học xã hội và sự thành bại của các quốc gia [Social science and the success of nations]. Tạp chí Khoa học xã hội Việt Nam, 7(80).

Holcombe, R. (2012). Crony capitalism: By-product of big government. Independent Review 17(4), 541-559.

Huyen, T. (2015). Kinh te Viet Nam: Mat 15 nam chi 'do da qua song' [Vietnam economy: Takes 15 years just to 'explore rocks across rivers']. VTC News. Retrieved February 20, 2015, from https://vtc.vn/kinh-te-viet-nam-mat-15-nam-chi-de-do-da-qua-songar220716.html 
Kang, D. (2002). Crony capitalism: Corruption and development in South Korea and Philippines. Cambridge, England: Cambridge University Press.

Kang, D. (2003). Transaction costs and crony capitalism in East Asia. Comparative Politics, $35(4), 439-458$

Le, L. Q. (2014). Lợi ích nhóm, thục trạng và giải pháp [Group benefits, status quo and solutions] (pp. 96-97). Hanoi, Vietnam: NXB Chính Trị Quốc Gia.

MacIntyre, A. (2006). Crony capitalism in East Asia: Has anything changed? Paper present at East Asia a Decade after the Crisis, Australian National University, Canberra, Australia.

Mazumdar, S. (2008). Crony capitalism: Caricature or category? (Working Paper No. 2008/02). New Delhi, India: Institute for Studies in Industrial Development.

Mcmillan, J., \& Woodruff, C. M. (1998). Networks, trust, and search in Vietnam's emerging private sector. Retrieved February 21, 2015, from https://papers.ssrn.com/sol3/papers.cfm?abstract_id=99028

Nguyen, D. H. (2014). Tác động của các nhóm lợi ích đến việc ban hành chính sách [Impact of Interest Groups on Policy Release]. Tạp chí Khoa học xã hội Việt Nam, 12(85).

Nguyen, T., \& van Dijk, M. (2012). Corruption, growth, and governance: Private vs. stateowned firms in Vietnam. Journal of Banking \& Finance, 36, 2935-2948

Niskanen, W. (1971). Bureaucracy and representative government. Chicago, IL: AldineAtherton.

Olson, M. (1982). The rise and decline of nations. New Haven, CO: Yale University Press.

Roberts, J. (2010). Cronyism: Undermining economic freedom and prosperity around the world. Retrieved February 23, 2015, from https://www.heritage.org/internationaleconomies/report/cronyism-undermining-economic-freedom-and-prosperity-around-the

Rose-Ackerman, S. (1997). Corruption and government: Causes, consequences, and reform. Cambridge, UK: Cambridge University Press.

Sharafutdinova, G. (2011). Political consequences of crony capitalism inside Russia. In Contemporary european politics and society series. Notre Dame, IN: University of Notre Dame Press.

Stiglitz, J. (2000). Capital market liberalization, economic growth, and instability. World Development, 28(6), 1075-1086.

Truong, Q. (2015). The network-based economy in Vietnam. (Working Paper No. 2015/12). Maastricht, Netherlands: Maastricht School of Management.

Uddin, S. (2015). Privatization in Bangladesh: Emergence of family capitalism. Development and Change, 36(1), 157-182.

Vo, T. V. (2015). Nhóm lợi ích có nguy co lan rộng [Interest groups are at risk of spreading]. Retrieved February 23, 2015, from https://tuoitre.vn/loi-ich-nhom-co-nguy-co-lan-rong755004.htm 
Wee, V. (2002). Social fragmentation in Indonesia: A crisis from Suharto's new order, South East Asia (Working Paper No. 31). Hong Kong: Research Centre (SEARC), City University of Hong Kong.

You, S. (2005). Embedded autonomy or crony capitalism? explaining corruption in South Korea, relative to Taiwan and the Philippines, focusing on the Role of Land Reform and industrial policy. Paper presented at Annual meeting of American Political Science Association, Washington, DC. 